\title{
Reduced Bone Density in Children on Long-Term Warfarin
}

\author{
CHRIS BARNES, FIONA NEWALL, VERA IGNJATOVIC, PATRICIA WONG, FERGUS CAMERON, \\ GRAEME JONES, AND PAUL MONAGLE
}

\author{
Department of Haematology [C.B., F.N., V.I., P.W., P.M.], Departments of Endocrinology and Diabetes \\ [F.C.], Department of Paediatrics [P.M.], University of Melbourne, Royal Children's Hospital, Parkville, \\ 3052, Australia, Menzies Centre for Population Health Research [G.J.], Hobart 7000, Australia
}

\begin{abstract}
Vitamin $\mathrm{K}$ is essential for development of normal bone density and achieving adequate peak bone mass in childhood and is thought to be important in preventing the development of osteoporosis in later life. Warfarin, a vitamin $\mathrm{K}$ antagonist, is being used with greater frequency in children. The long-term effect of warfarin on bone density of children is not known. We performed a case control study survey of bone density in children on long-term warfarin ( $n=17$, average duration of warfarin treatment 8.2 y) compared with randomly selected controls $(n=$ 321). There was a marked reduction in bone mineral apparent density of lumbar spine between patients and controls [patients $0.10 \mathrm{~g} / \mathrm{cm}^{3} ; 95 \%$ confidence interval (CI), $0.93-0.11 \mathrm{~g} / \mathrm{cm}^{3}$,
\end{abstract}

\section{ABSTRACT}

controls $\left.0.12 \mathrm{~g} / \mathrm{cm}^{3} ; 95 \% \mathrm{CI}, 0.11-0.12 \mathrm{~g} / \mathrm{cm}^{3}, p<0.001\right)$. The lumbar spine areal bone mineral density Z-score of patients was reduced compared with controls [patients, -1.96 (95\% CI, -2.52 to -1.40 ). This difference persisted after adjustment for age and body size. The etiology for the reduced bone density is likely to be multifactorial, however, screening of children on long-term warfarin for reduced bone density should be considered. (Pediatr Res 57: 578-581, 2005)
BMAD, bone mineral apparent density BMD, bone mineral density

The use of warfarin in children is increasing as a result of the increased incidence of pediatric thromboembolic disease (1). There is little published data on the effect of long-term warfarin in children.

Warfarin, a vitamin $\mathrm{K}$ antagonist, affects the carboxylation of glutamic acid (Gla) residues of vitamin $\mathrm{K}$-dependent proteins. Carboxylated proteins have a high affinity for calcium and are important in the incorporation of calcium into bone and bone formation (2). At least three carboxylated proteins have been identified within the bony matrix (3). Osteocalcin, the most abundant of these proteins, is produced by osteoblasts during new bone matrix formation (4). Vitamin K deficiency, as demonstrated by levels of undercarboxylated osteocalcin, is an independent predictor of osteoporosis and hip fracture in elderly women (5).

Because the most important period of bone mineral acquisition is during late childhood and adolescence, long-term

Received January 29, 2004; accepted August 13, 2004

Correspondence: Paul Monagle, M.D., Royal Children's Hospital, Flemington Rd., Parkville 3052, Victoria, Australia; e-mail: paul.monagle@wch.org.au

Chris Barnes is supported by a medical postgraduate grant from the National Health and Medical Research Council Grant. Paul Monagle is supported by a part-time salary grant from the Murdoch Children's Research Institute. Graeme Jones is supported by a National Health and Medical Research Council Practitioner Fellowship.

DOI: 10.1203/01.PDR.0000155943.07244.04 treatment with warfarin in children may lead to suboptimal bone mineral acquisition. Adequate bone mass accumulation in early life is important in preventing both fractures in children and osteoporosis in later life $(6-8)$. The aim of the current study was to describe results of bone density scans performed on children on long-term warfarin and compare results to randomly selected controls.

\section{METHODS}

Subjects. Patients on warfarin for $>12$ mo and managed by the anticoagulation clinic at the Royal Children's Hospital, Melbourne, Australia, have bone scans performed as part of routine management. The indication for warfarin therapy in all patients in the present study was complex congenital heart disease. Details regarding date of initiation and duration of warfarin therapy were collected from the patients' medical records.

Bone densitometry. Bone density of the lumbar spine, incorporating L1L4, on patients was assessed using Hologic QDR 4500 Elite densitometer (Hologic, Bedford, MA). The coefficient of variation using a spine phantom was $0.39 \%$.

BMD results are traditionally reported as areal $\mathrm{BMD}\left(\mathrm{g} / \mathrm{cm}^{2}\right)$, which is calculated by dividing the quantity of the BMC $(\mathrm{g})$ by the area of interest. Areal BMD calculations, however, have been shown to underestimate the bone density in short children and not accurately reflect changes occurring in bone geometry during puberty (9). The calculation of BMAD $\left(\mathrm{g} / \mathrm{cm}^{3}\right)$ is an approximation of the volumetric density of bone calculated from the BMC and the projected area of bone. We used the calculation of BMAD according to that described by Katzman et al. (10) where the volume of the measured spine is approximated by $\mathrm{A}^{3 / 2}$, where $\mathrm{A}$ is the projected area of the measured vertebrae.

Interpretation of bone density results of different aged children can be facilitated by reporting results as a SD score or Z-score. A Z-score is defined 
as the number of SD above or below the mean using age- and sex-matched reference data.

Anthropometric data. Height was measured without shoes to the nearest 1.0 $\mathrm{cm}$ using a standard Harpenden wall-mounted stadiometer. Weight was measured with light indoor clothing, without shoes to the nearest $1.0 \mathrm{~kg}$ using standard electronic scales. Body mass index (BMI) was calculated using the standard formula. To facilitate interpretation of patient anthropometric data, the BMI of patients' values were converted to Z-scores.

Controls. Control patients were identified as described in Ma and Jones (7). Briefly, control subjects were fracture free and randomly selected from schools in Southern Tasmania as part of a population-based case control study investigating the association between reduced bone density and upper limb fracture in children aged 9-16 y. Lumbar spine (L1-L4) BMD for controls was measured using Hologic QDR 2000 densitometer. The longitudinal coefficient of variation using daily measurements of a spine phantom for the QDR 2000 was $0.50 \%$. Although there is evidence that results between Hologic densitometers are transferable, (11) there was no attempt to verify results between the two densitometers in our study.

Statistical analysis. Results are expressed as a mean with 95\% confidence limits or SD. A $p$ value of $<0.05$ is considered significant. Comparisons between different groups of patients were carried out using a two-tailed unpaired $t$ test. Univariate and multivariate analysis was used to determine the significance of differences in height and weight on the difference in bone density of patients on long-term warfarin compared with controls. Univariate and multivariate analysis was performed using SPSS software (version 8.0 for Windows; SPSS Inc., Chicago, IL). All other analyses were performed with STATA software (version 8.0; StataCorp, College Station, TX).

\section{RESULTS}

Patients and demographics. Seventeen patients (9 males, 8 females) had bone density scans performed. The mean age of patients was 14.7 y (range, $8.6-18.8$ y). Fourteen patients had cyanotic heart disease and 3 patients had acyanotic heart disease. One patient was receiving a medication known to affect bone density (corticosteroids). Two patients were receiving calcium supplements before bone density measurement.

The mean age at which warfarin was commenced was $6.8 \mathrm{y}$ (range, 0.3-14.8 y). The mean duration of treatment with warfarin was 8.2 y (range, $1.0-14.0 \mathrm{y}$ ).

Three hundred and twenty-one control subjects (215 males, 106 females) were recruited as described.

Anthropometric data. The anthropometric data of patients and controls are listed in Table 1 . There was no statistically significant difference in height or weight between patients and controls. The mean BMI Z-score of patients approached 0 at -0.27 (95\% confidence limits, -0.81 to 0.25 ).

\section{BMD}

The mean BMC, areal BMD, and BMAD are listed in Table 1. There was a significant difference in BMAD between patients $\left[0.10 \mathrm{~g} / \mathrm{cm}^{3}\left(95 \%\right.\right.$ confidence limits, $\left.\left.0.09-0.11 \mathrm{~g} / \mathrm{cm}^{3}\right)\right]$

Table 1. Comparison of patients on long-term warfarin and controls

\begin{tabular}{lccc}
\hline & $\begin{array}{c}\text { Warfarin } \\
(n=17) \\
\text { Mean }(\mathrm{SD})\end{array}$ & $\begin{array}{c}\text { Controls } \\
(n=321)\end{array}$ & \\
& Mean $(\mathrm{SD})$ & $p$ Value \\
\hline Age $(\mathrm{y})$ & $14.7(2.4)$ & $12.5(2.2)$ & $<0.001$ \\
Weight $(\mathrm{kg})$ & $47(15)$ & $50(17)$ & 0.36 \\
Height $(\mathrm{cm})$ & $154(14)$ & $155(15)$ & 0.17 \\
Spine BMC $(\mathrm{g})$ & $38(13)$ & $38(16)$ & 0.90 \\
Area $\left(\mathrm{cm}^{2}\right)$ & $51.7(8.7)$ & $46.3(10.4)$ & 0.04 \\
Spine BMD $\left(\mathrm{g} / \mathrm{cm}^{2}\right)$ & $0.725(0.146)$ & $0.787(0.156)$ & 0.12 \\
Spine BMAD $\left(\mathrm{g} / \mathrm{cm}^{3}\right)$ & $0.101(0.015)$ & $0.116(0.016)$ & $<0.001$ \\
\hline
\end{tabular}

and controls $\left[0.12 \mathrm{~g} / \mathrm{cm}^{3}\right.$ (95\% confidence limits, $0.11-0.12$ $\left.\left.\mathrm{g} / \mathrm{cm}^{3}\right)\right], p<0.001$. The BMAD Z-score of patients is reduced compared with controls: patients -1.96 (95\% confidence limits, -2.52 to -1.40 ; Fig. 1). Multivariate analysis showed the observed difference in BMAD increased when adjustments were made for age, body weight, and height (Table 2).

\section{DISCUSSION}

Children with congenital heart disease treated with longterm warfarin at the Royal Children's Hospital have significantly reduced bone density compared with controls. Although the etiology of reduced bone density in our patient group is likely to be multifactorial, the potential effect of warfarin on vitamin $\mathrm{K}$-dependent proteins necessary for bone formation suggests long-term warfarin may have a impact on bone density in children. Considering the benefit of early identification of children at risk of osteoporosis, we suggest children on long-term warfarin should be considered for screening for reduced bone density. Further studies examining the direct effect of long-term warfarin on bone density of children are required.

The use of warfarin in children is rising and is directly related to the increasing incidence of thromboembolic disease in children (1). Reasons for this increase include the greater use of central venous lines and the improved survival of children with congenital heart disease (1). Central venous lines are used to provide essential short- and long-term venous access for a number of life-threatening conditions in children and remain the major risk factor for a child developing venous thrombosis (1). Warfarin remains the mainstay of treatment of thromboembolic disease in children. This is despite a limited understanding of the significance of long-term effects of inhibition of vitamin $\mathrm{K}$-dependent proteins in growing children.

A number of studies have investigated the association between warfarin and reduced bone density and osteoporosis in adult patients $(2,12-15)$. The results of these studies are conflicting and some of these studies are small cohort studies and had short follow-up periods. In one large study of 6314 personyears follow-up, long-term exposure to warfarin was associ-

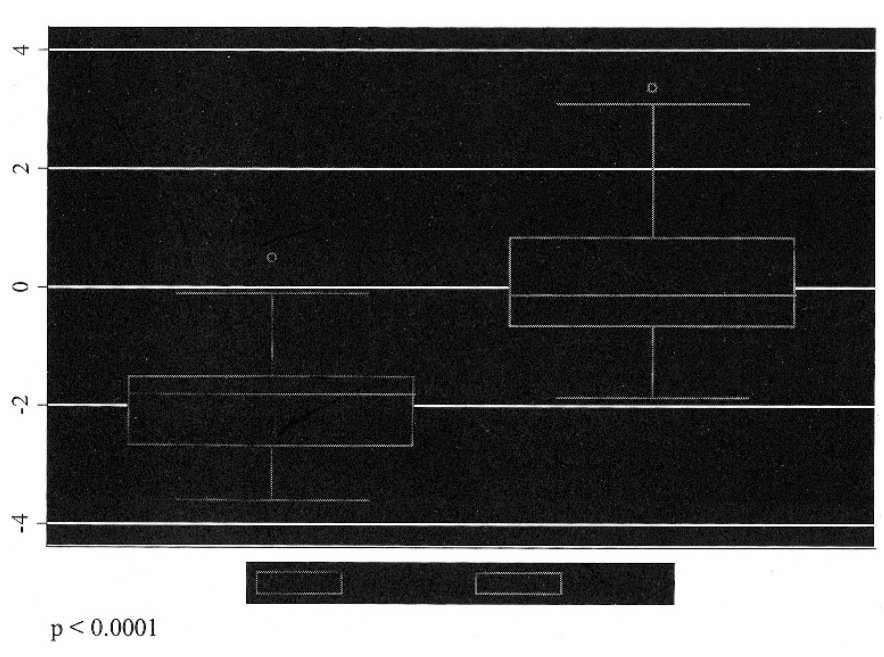

Figure 1. Areal lumbar BMD Z-score of patients on long-term warfarin. 
Table 2. Univariate and multivariate analysis of warfarin usage and bone mass

\begin{tabular}{lll}
\hline & \multicolumn{1}{c}{ Univariate $\beta(95 \% \mathrm{CI}, p$ value $)$} & \multicolumn{1}{c}{ Multivariate* $\beta(95 \%$ CI, $p$ value $)$} \\
\hline BMC $(\mathrm{g})$ & $+0.5(-7.0,+8.0, p=0.90)$ & $-1.9(-6.1,+2.3, p=0.38)$ \\
$\mathrm{BMD}\left(\mathrm{g} / \mathrm{cm}^{2}\right)$ & $-0.06(-0.14,+0.02, p=0.12)$ & $-0.09(-0.14,-0.04, p<0.001)$ \\
$\mathrm{BMAD}\left(\mathrm{g} / \mathrm{cm}^{3}\right)$ & $-0.015(-0.023,-0.007, p<0.001)$ & $-0.016(-0.023,-0.009, p<0.001)$ \\
\hline
\end{tabular}

95\% CI, 95\% confidence interval.

* Adjusted for age, sex, height, and weight.

ated with an increased rate of vertebral and rib fractures (13). On the other hand, a study of 6052 adult patients followed for more than $3 y, 149$ of who were treated with warfarin, showed no difference in bone density or rate of fracture in the patients receiving warfarin (12). A recent meta-analysis of nine crosssectional surveys showed warfarin exposure was associated with a reduction of $0.4 \mathrm{SD}$ in bone density of the radius but no significant change in bone density of the hip or spine (16). This suggests that warfarin may be associated with only a modest increase in the risk of osteoporosis in adult patients.

Additional factors are likely to be important in the etiology of reduced bone density in our study population. Weightbearing exercise is critical to ensure adequate bone mass accrual in childhood (17). The exact mechanism by which weight loading increases bone mass is not known but is likely related to dynamic strains engendered in bone tissue regulating bone formation and resorption (18). No attempt to assess the exercise tolerance of the children we studied was made, however, the ability of children with congenital heart disease to participate in dynamic weight bearing exercise may be limited. Dietary factors, in particular, dietary deficiency of calcium and vitamin $\mathrm{D}$, may also be important in our patients. No attempt to quantify adequacy of calcium and vitamin $\mathrm{D}$ intake was made. The fact that the difference in bone density was independent of body size compared with controls suggests, however, that dietary factors may not be a major factor in contributing to reduced bone density in our patients.

Pubertal development has a very important influence on the development of bone density. Bone metabolism during adolescence is affected by changes in rising levels of sex hormone secretion and peak growth hormone and insulin-like growth factor-1 secretion (19). It is estimated that $45 \%$ of bone mineral acquisition occurs during puberty, and pubertal delay has been associated with reduced bone density in a number of different chronic illnesses including anorexia nervosa, males with constitutional pubertal delay, and thalassemia (20-23). There are no studies on the incidence of pubertal delay in children with congenital heart disease, and no assessment of pubertal delay was made in the patients of our study. Because pubertal delay affects growth, we believe the persistence of a reduction in bone density between patients and controls when adjusted for parameters of growth (height, weight, and age) suggests that pubertal delay is not a major contributor to reduced bone density in our patients.

A number of therapies exist for children with reduced bone density $(6,24)$. Exercise intervention trials have demonstrated a beneficial and durable effect of high-impact exercise on bone density of children (25). Developing exercise programs to manage low bone density in patients with congenital heart disease may be problematic but programs incorporating jump- ing have been shown to improve bone mass in children and may have limited demand on the cardiovascular system (26). Calcium and vitamin D supplementation can be used to increase spinal BMD (6). Bisphosphonate therapy has been effective in treating children with metabolic bone disease and osteoporosis, but a number of issues, including optimal dose and duration of therapy in children, need to be resolved and studies documenting an association with a clinical outcome such as fracture would be required before bisphosphonate therapy is considered (24).

A strength of this study is that we used randomly selected population based controls, which provides both a representative sample for comparison and facilitated assessment of the important question as to whether the deficit in bone mass was due to smaller body size or a reflection of true bone density. In our geographic location, there is no acceptable reference database for children and locally sourced controls were desirable. However, the controls were not from the same source population as the cases and bone density was measured using different instruments by different technicians. Although Southern Tasmania is similar in latitude to Victoria and has remarkably similar total fracture incidence rates in adults (27), there is no comparative data between the two regions for bone density in children. However, recent work has found only very small differences in bone density between control populations in Hobart, Sydney, and New Zealand (M. Henry, unpublished data). Also, longitudinal coefficients of variations against a spinal dummy were consistently low for both the instruments, and, therefore, any potential differences due to location bias are very unlikely to explain the large difference we observed between cases and controls in the current study.

In conclusion, our study demonstrates significantly reduced bone density in children with congenital heart disease treated with long-term warfarin. Although there is a putative explanation for warfarin in causing reduced BMD in children, the etiology is likely to be multifactorial. Screening of children on long-term warfarin for reduced bone density is recommended and further investigation into the etiology for reduced BMD is necessary.

\section{REFERENCES}

1. Andrew M, Monagle P, Brooker L 2000 Epidemiology of venous thromboembolic events. In: Monagle P, Andrew M, Brooker L (eds) Thromboembolic Complications of Infancy and Childhood. Decker, Hamilton, ON, Canada, pp 111-146

2. Booth S, Mayer J 2000 Warfarin use and fracture risk. Nutr Rev 58:20-22

3. Zittermann A 2001 Effects of vitamin K on calcium and bone metabolism. Curr Opin Clin Nutr Metab Care 4:483-487

4. Shearer MJ 1995 Vitamin K. Lancet 345:229-234

5. Feskanich D, Weber P, Willett WC, Rockett H, Booth SL, Colditz GA 1999 Vitamin $\mathrm{K}$ intake and hip fractures in women: a prospective study. Am J Clin Nutr 69:74-79

6. NIH Consensus Development Panel on Osteoporosis Prevention Diagnosis and Therapy 2001 Osteoporosis prevention, diagnosis, and therapy. JAMA 285:785-795 
7. Ma D, Jones G 2003 The association between bone mineral density, metacarpal morphometry, and upper limb fractures in children; a population based case control study. J Clin Endocrinol Metab 88:1486-1491

8. Goulding A, Cannan R, Williams SM, Gold EJ, Taylor RW, Lewis-Barned NJ 1998 Bone mineral density in girls with forearm fractures. J Bone Miner Res 13:143-148

9. Glastre C, Braillon P, David L, Cochat P, Meunier PJ, Delmas PD 1990 Measurement of bone mineral content of the lumbar spine by dual energy $\mathrm{x}$-ray absorptiometry in normal children: correlations with growth parameters. J Clin Endocrinol Metab 70:1330-1333

10. Katzman D, Bachrach LK, Carter DR, Marcus R 1991 Clinical and anthropometric correlates of bone mineral acquisition in healthy adolescent girls. J Clin Endocrino Metab 73:1332-1339

11. Prince R, Price R, Gutteridge D, Retallack R, Dick I 1995 Comparison of bone mineral density measurement between Hologic QDR2000 and the QDR4500A. J Bone Miner Res 10:S487

12. Jamal SA, Browner WS, Bauer DC, Cummings SR 1998 Warfarin use and risk for osteoporosis in elderly women. Study of Osteoporotic Fractures Research Group. Ann Intern Med 128:829-832

13. Caraballo PJ, Heit JA, Atkinson EJ, Silverstein MD, O'Fallon WM, Castro MR, Melton LJ III 1999 Long-term use of oral anticoagulants and the risk of fracture. Arch Intern Med 159:1750-1756

14. Fiore CE, Tamburino C, Foti R, Grimaldi D 1990 Reduced axial bone mineral content in patients taking an oral anticoagulant. South Med J 83:538-542

15. Philip WJ, Martin JC, Richardson JM, Reid DM, Webster J, Douglas AS 1995 Decreased axial and peripheral bone density in patients taking long term warfarin. QJM 88:635-640

16. Caraballo PJ, Gabriel SE, Castro MR, Atkinson EJ, Melton LJ III 1999 Changes in bone density after exposure to oral anticoagulants: a meta-analysis. Osteoporos In 9:441-448

17. Bradney M, Pearce G, Naughton G, Sullivan C, Bass S, Beck T, Carlson J, Seeman E 1998 Moderate exercise during growth in pre-pubertal boys: changes in bone mass, size, volumetric density, and bone strength: a controlled prospective study. J Bone Miner Res 13:1814-1821

18. Lanyon LE 1996 Using functional loading to influence bone mass and architecture: objectives, mechanisms, and relationship with estrogen of the mechanically adaptive process in bone. Bone 18:37S-43S

19. Attie KM 2000 The importance of growth hormone replacement therapy for bone mass in young adults with growth hormone deficiency. J Pediatr Endocrinol Metab 13:1011-1021

20. del Rio L, Carrascosa A, Pons F, Gusinye M, Yeste D, Domenech FM 1994 Bone mineral density of the lumbar spine in white Mediterranean Spanish children and adolescents: changes related to age, sex, and puberty. Pediatr Res 35:362-366

21. Bielinski BK, Darbyshire PJ, Mathers L, Crabtree NJ, Kirk JM, Stirling HF, Shaw NJ 2003 Impact of disordered puberty on bone density in beta-thalassaemia major. Brit J Haematol 120:353-358

22. Finkelstein JS, Klibanski A, Neer RM 1996 A longitudinal evaluation of bone mineral density in adult men with histories of delayed puberty. J Clin Endocrinol Metab $81: 1152-1155$

23. Munoz MT, Argente J 2002 Anorexia nervosa in female adolescents: endocrine and bone mineral density disturbances. Eur J Endocrinol 147:275-286

24. Batch JA, Couper JJ, Rodda C, Cowell CT, Zacharin M 2003 Use of bisphosphonate therapy for osteoporosis in childhood and adolescence. J Paediatr Child Health 39:88-92

25. Fuchs RK, Snow CM 2002 Gains in hip bone mass from high-impact training are maintained: a randomized controlled trial in children. J Pediatr 141:357-362

26. Fuchs RK, Bauer JJ, Snow CM 2001 Jumping improves hip and lumbar spine bone mass in prepubescent children: a randomized controlled trial. J Bone Miner Res $16: 148-156$

27. Cooley H, Jones G 2001 A population based study of fracture incidence in southern Tasmania: lifetime fracture risk and evidence for geographic variations within the same country. Osteoporos Int 12:124-130 